\title{
Assessing a risk-avoidance navigation system based on localized torrential rain data
}

\author{
Sadanori Ito ${ }^{1, a}$ and Zettsu Koji ${ }^{1}$ \\ ${ }^{1}$ NICT Big Data Analytics Laboratory, National Institute of Information and Communications Technology, Nukuikitamachi 4-2-1, Koganei, \\ Tokyo 184-8795, Japan
}

\begin{abstract}
Localized torrential rainfall events and related traffic problems are increasing in Japan, suggesting the need for a navigation-alert system to help drivers avoid such risks. Based on ongoing developments of weather radar systems for early detection of localized torrential rain and a cross-data collaboration platform for traffic optimization, in this study we tested the application of a route-guidance system that can help drivers avoid heavy rainfall. Participants were given equivalent levels of pre-training un the early detection of rainfall and the relationship between rainfall and accidents, then allowed to test a driving simulator set up with four alert methods, three route options, and four levels of possible risk avoidance. Using this system, the heavy rain avoidance rate was $85.63 \%$, suggesting that such a system would be socially acceptable and useful, though further research is needed to refine the specific approach.
\end{abstract}

\section{Introduction}

Torrential rain events have recently become more common in Japan [1,2], along with increasing traffic problems caused by unusual weather [3]. Heavy rain raises driving risk [4-6] due to lowered visibility $[7,8]$ and road friction [9]. While localized short-term heavy rain is difficult to predict [10], its narrow coverage makes it possible to avoid through altered travel routes. The Japanese National Institute of Information and Communications Technology (NICT) is developing a weather radar system intended for the early detection and prediction of localized torrential rain [11], while also developing a cross-data collaboration platform [12] to optimize navigation by collecting information related to traffic risks such as various IoT sensor data including those from weather radar (Figure 1). This approach may allow localized torrential rain to be treated as a traffic risk and provide route guidance for avoidance. Although it is widely known that extreme weather affects traffic behaviour [13], it is unclear whether guidance to avoid heavy rain would be used by drivers to avoid accidents and traffic congestion. Thus, in this study we used observed rainfall and actual travel routes to investigate whether heavy rain information would be used by drivers for risk avoidance. In addition, we investigated whether the method of information provision affected driver behaviour.

\footnotetext{
${ }^{a}$ Corresponding author: sadanori.ito@nict.go.jp
}

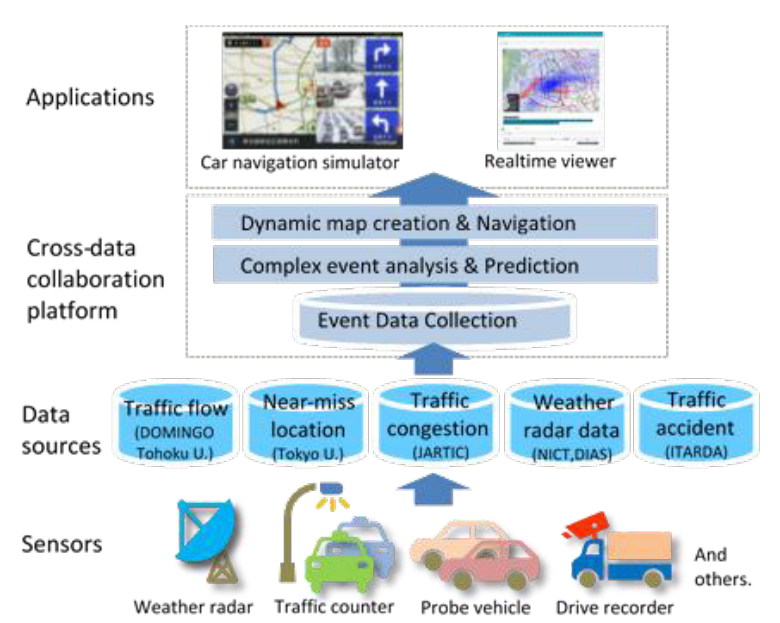

Figure 1. Configuration of cross-data collaboration platform.

\section{Methods}

\subsection{Participants}

A total of 30 participants (20 male and 10 female, 20-50 years old) were recruited; each had more than 3 years driving experience.

\subsection{Pre-experiment lecture}

Decision-making in risk situations relies heavily on personal knowledge and conditions [14]. To ensure an equal experimental baseline, all participants were given a 
one-hour pre-experimental lecture covering (1) statistical evidence of the relationship between rainfall and accidents, (2) scientific analysis of accidents during rainfall (loss of friction and visual deterioration), (3) reliability of prediction and avoidance of localized heavy rainfall using MP-PAWR weather radar, (4) examples of accidents caused by heavy rain, and (5) example film of a driver's view in heavy rain. Furthermore, as the choice of travel route depends on personal situation (such as commuting or leisure) [15], we instructed all participants to assume that they were driving with family on a holiday, allowing for plenty of time and prioritizing safety. All were instructed on proper use of the experimental apparatus.

\subsection{Apparatus}

The experimental apparatus (Figure 2) was designed to simulate vehicular operation using a large display and a steering wheel controller (DFKI OpenDS) with mapbased navigational information (such as the car's current location) provided by a synchronized display screen (an Android tablet (HUAWEI MadiaPad M3 Lite) with 8" display).

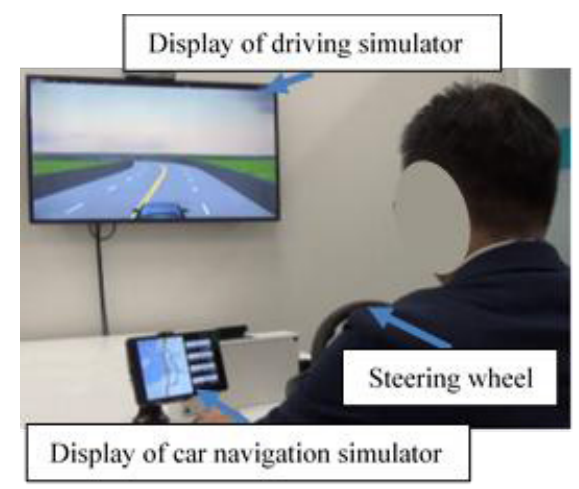

Figure 2. Layout of experimental apparatus.

\subsection{Procedure}

We designed a procedure based on a dual-task paradigm [16] that allows simultaneous driving and decisionmaking tasks to best simulate an actual driving situation. The primary driving task required participants to follow the road's centre line while driving a course with gentle curves to left and right that simulated a steady attention load on the driver. The maximum vehicle speed was fixed at $30 \mathrm{~km} / \mathrm{h}$ by the configuration, but the participant was asked to continue driving at a constant speed by continuing to depress the accelerator. When looking at the route selection display, the participants were instructed to stop as necessary to ensure safety.

The secondary task required the participants to make decisions based on alert messages and route selection (Figure 3). At a pre-set location on the navigation simulator's map displayed the current position of the vehicle on a map. At a pre-set location on the navigation simulator's map, an alert message was displayed, at which point the participant selected whether or not to refer to the route selection screen. In that screen, participants were given the option to select a route that reduced the risk of traffic. We randomly presented 4 types of alert messages and 3 types of route selection screens, performing as many trials as possible within a time limit of about 30 minutes.

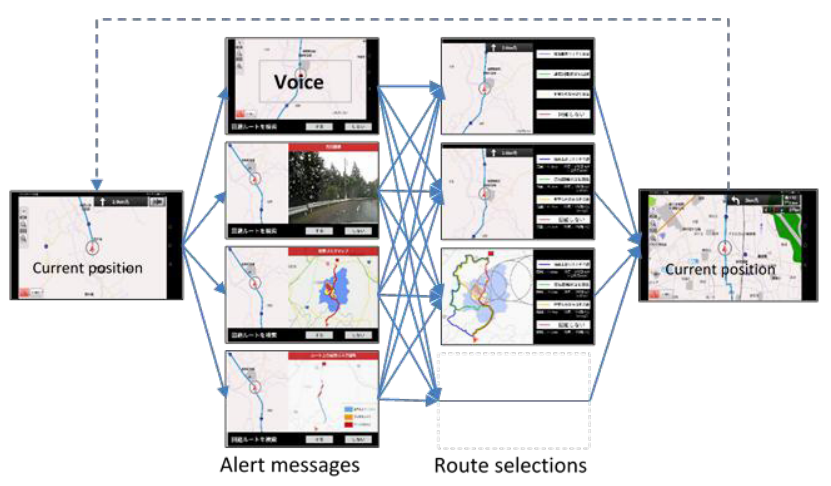

Figure 3. Schematic diagram of the trial procedure, in which drivers are given one of four alerts and one of three route selection options, based on their current simulated location.

\subsection{Stimuli}

In order to reproduce realistic situations, we used localized torrential rain events recorded by MP-PAWR weather radar [11]. From the radar precipitation maps, we created three traffic risk maps in which the driving environment deterioration was indexed from 0 to 10 (Figure 4) using "Class of rain and wind. [17]" Four possible travel routes were set for each risk map at different levels of risk avoidance (Table 1).

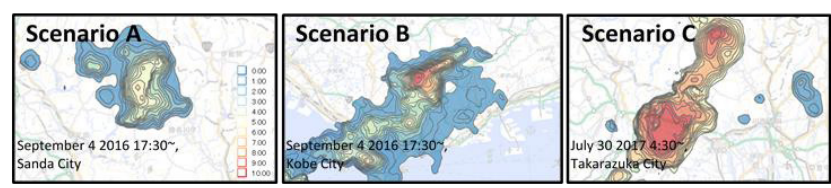

Figure 4. Risk maps for the three scenarios.

Table 1. Travel route specifications.

\begin{tabular}{|c|c|c|c|c|}
\hline \multirow[b]{2}{*}{ Scenario } & \multicolumn{4}{|c|}{ Travel routes } \\
\hline & $\begin{array}{l}\text { Avoid risk } \\
\text { Lv. } 1 \text { or more }\end{array}$ & $\begin{array}{l}\text { Avoid risk } \\
\text { Lv. } 3 \text { or more }\end{array}$ & $\begin{array}{l}\text { Avoid risk } \\
\text { Lv. } 6 \text { or more }\end{array}$ & $\begin{array}{l}\text { Do not avoid } \\
\text { risks. }\end{array}$ \\
\hline A & $\begin{array}{l}41.8 \mathrm{~km} \text {, } \\
196 \mathrm{~min} .\end{array}$ & $\begin{array}{l}49.3 \mathrm{~km} \text {, } \\
116 \mathrm{~min} .\end{array}$ & $\begin{array}{l}41.7 \mathrm{~km} \text {, } \\
102 \mathrm{~min} .\end{array}$ & $\begin{array}{r}27.3 \mathrm{~km} \text {, } \\
62 \mathrm{~min} .\end{array}$ \\
\hline B & $\begin{array}{l}44.8 \mathrm{~km} \text {, } \\
118 \mathrm{~min} .\end{array}$ & $\begin{array}{r}29.8 \mathrm{~km}, \\
70 \mathrm{~min} .\end{array}$ & $\begin{array}{r}26.5 \mathrm{~km}, \\
62 \mathrm{~min} .\end{array}$ & $\begin{array}{r}25.5 \mathrm{~km} \text {, } \\
54 \mathrm{~min} .\end{array}$ \\
\hline $\mathrm{C}$ & $\begin{array}{l}88.5 \mathrm{~km} \text {, } \\
196 \mathrm{~min} .\end{array}$ & $\begin{array}{l}36 \mathrm{~km} \text {, } \\
84 \mathrm{~min} .\end{array}$ & $\begin{array}{l}35.7 \mathrm{~km} \text {, } \\
83 \mathrm{~min} .\end{array}$ & $\begin{array}{l}30.6 \mathrm{~km} \text {, } \\
41 \mathrm{~min} .\end{array}$ \\
\hline
\end{tabular}

\subsubsection{Alert messages.}

In the "Voice only" alert message, a voice stated that "Torrential rain is occurred along your travel route. Do you want to bypass?" In the other three message, this statement was played along with other stimuli. In the "Picture of high-risk spot" message, a simulated picture 
captured by a recorder on a preceding vehicle was displayed. In the "Risk map" message, the travel route and risk map were displayed. In the "Simplified route with risk" message, color-coded risk values were displayed along the route map [18]. In each case, "See avoidance route (Yes / No)" was displayed at the bottom of the screen. If the button was not pressed after 20 seconds or the "No" button was pressed, the screen was returned to the current position map. If the "Yes" button was pressed, the screen changed to a route selection screen.

\subsubsection{Route selection.}

The first route selection screen had four buttons with short descriptions of each route: (1) "Avoid areas where accident risk increases due to rainfall (Avoid risk level 1 or more)", (2) "Avoid areas where driving difficulties occur (Avoid risk level 3 or more)", (3) "Avoid dangerous areas (Avoid risk level 6 or more)" and (4) "Continue driving without considering torrential rain." The second type also displayed numerical values for distance and travel time, while the third type included also displayed risk maps and movement forecasts for high-risk areas. The specific situations represented by each evaluation and risk value had been defined in the pre-experimental lectures.

\section{Results}

The 183 total trials were divided between scenarios $\mathrm{A}$ (71), B (55), and C (57). Each participant conducted 5-8 trials, which varied due to the time limit. The order of trials was considered to avoid bias in order effect.

\subsection{Alert messages}

The alert was accepted 160 times (87.43\%), displaying detailed information on the route selection screen. A binomial test indicated that the proportion of acceptance (.87) was higher than the expected $.5, \mathrm{p}<.01$. This may be because heavy rain was the target event of avoidance. A Pearson's chi-square test of independence was performed to examine the relationship between alert message type and acceptance rate, which was not statistically significant $(\mathrm{X} 2(\mathrm{~N}=183)=2.43, \mathrm{p}=.49)$. The mean reaction time was $9.24 \mathrm{sec}(\mathrm{SD}=3.23$; Table 2 and Figure 5). The Brunner-Munzel test was conducted to compare each alert type; there was no a significant difference between all relationships; $\mathrm{p}>.05$. These results suggest that alert type did not affect reaction time.
Table 2. Trial number $(\mathrm{Nt})$, acceptance rate, and reaction time for each stimulus.

\begin{tabular}{|l|l|l|l|l|l|}
\hline $\begin{array}{l}\text { Alert } \\
\text { type }\end{array}$ & $\mathrm{Nt}$ & Acceptance & \multicolumn{3}{|c|}{ Reaction time (sec.) } \\
\cline { 4 - 6 } & & & $(\mathrm{mean})$ & $(\mathrm{sd})$ & $\left(\mathrm{mode}^{\mathrm{l}}\right)$ \\
\hline Voice & 58 & $48(82.76 \%)$ & 9.02 & 2.93 & 7.90 \\
\hline Photo & 41 & $37(90.24 \%)$ & 8.50 & 2.40 & 6.35 \\
\hline $\begin{array}{l}\text { Mesh } \\
\text { map }\end{array}$ & 44 & $38(86.36 \%)$ & 9.19 & 2.84 & 6.10 \\
\hline $\begin{array}{l}\text { Simple } \\
\text { route }\end{array}$ & 40 & $37(92.50 \%)$ & 10.38 & 4.31 & 5.70 \\
\hline Total & 183 & $\begin{array}{l}160 \\
(87.43 \%)\end{array}$ & $\mathrm{n} / \mathrm{a}$ & $\mathrm{n} / \mathrm{a}$ & $\mathrm{n} / \mathrm{a}$ \\
\hline
\end{tabular}

'modal class interval $=100 \mathrm{~ms}$

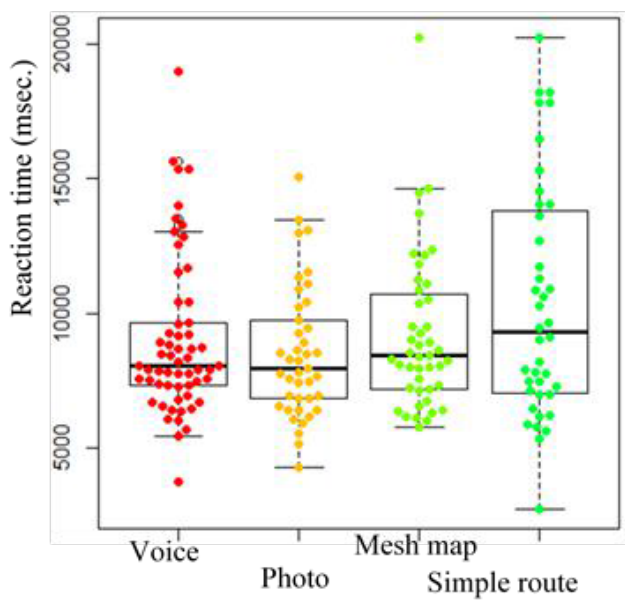

Figure 5. Reaction time to alert messages.

\subsection{Route selection}

Once the alert was selected, the avoidance rate for all options was $85.63 \%$ (Table 3). A binomial test indicated that the proportion of avoidance $(.85)$ was higher than the expected $.5, \mathrm{p}<.01$. The Cramer's V was calculated as a measure of association between the type of route selection display and the selection; the results (Cramer's $\mathrm{V}=.18$ ) showed a moderate relationship.

Table 3. Route selection results.

\begin{tabular}{|c|c|c|c|c|c|}
\hline \multirow{2}{*}{$\begin{array}{l}\text { Selection } \\
\text { type }\end{array}$} & \multicolumn{5}{|c|}{ Route selection results } \\
\hline & $\begin{array}{l}\text { Avoid } \\
\text { Risk } 1 \\
\text { or } \\
\text { more }\end{array}$ & $\begin{array}{l}\text { Avoid } \\
\text { Risk } 3 \\
\text { or } \\
\text { more }\end{array}$ & $\begin{array}{l}\text { Avoid } \\
\text { Risk } 6 \\
\text { or } \\
\text { more }\end{array}$ & $\begin{array}{l}\text { Do not } \\
\text { avoid } \\
\text { risks }\end{array}$ & Total \\
\hline $\begin{array}{l}\text { Short } \\
\text { description }\end{array}$ & 15 & 29 & 15 & 7 & 66 \\
\hline $\begin{array}{l}+ \text { Values of } \\
\text { distance and } \\
\text { duration }\end{array}$ & 5 & 18 & 20 & 7 & 50 \\
\hline $\begin{array}{l}+ \text { Risk map, } \\
\text { routes, and } \\
\text { prediction }\end{array}$ & 5 & 21 & 9 & 9 & 44 \\
\hline Total & 25 & 68 & 44 & 23 & 160 \\
\hline
\end{tabular}




\section{Discussion}

Our results suggest that localized torrential rain information could be accepted by drivers as a reason for travel route modification. However, differences in information transmission method remain unclear. The difference in the acceptance rate of alert message type was not statistically significant. This may be attributable to the fixation of drivers' situation, the small difference in information reliability due to the pre-experiment lecture, and the low number of trials. Further experiments may be needed to assess driver situation and information reliability.

The alert type did not affect reaction time. The average value of the simplified route type was the longest, but the mode was the shortest (Table 2). F-test results showed that the variances of simplified route type and other types were not equal, which could be affected by inadequate pre-experiment lectures regarding simplified route type representation. In any case, there were no differences worth considering for practical use. Although these results are somewhat unclear, we suggest that the voice option should be adopted, as this is less likely to inhibit driving.

There was a characteristic increase in the avoidance of low-risk situations for the short description type (Figure 6), which may have been caused by the inability to properly compare the risk and cost. This could reduce the reliability of the system in the long term. Also, the "Do not avoid" option increased with a higher level of description, possibly because the risk movement prediction overlaps the route for avoidance. It seems that the risk avoidance benefit was doubted. This acceptability of the movement prediction information requires additional verification.

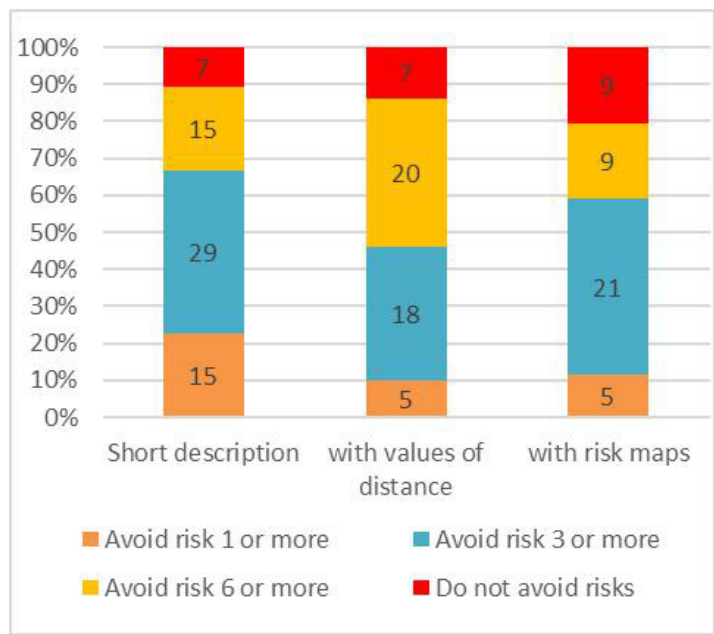

Figure 6. Results of route selection.

We conducted an impression evaluation of participants to examine the relationship between type of route selection display and selection result (Figure 7); the amount of information was highly evaluated. The short description ranked well below the others in sufficiency of information, while the risk map ranked well above the others for clarity of representation, suggesting that cost comparison and graphic representation had a certain effect.

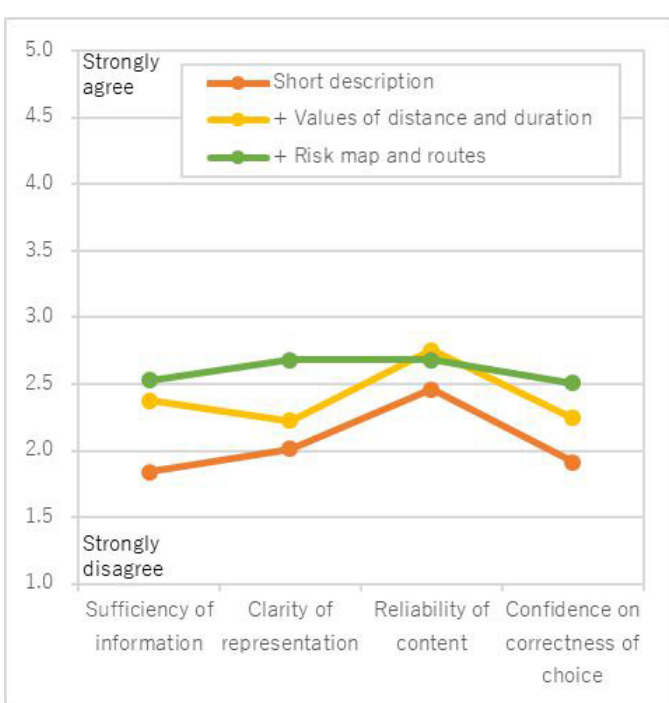

Figure 7. Impression evaluation of representation of route selection display.

\section{Conclusion}

We tested the acceptability of an application that uses localized torrential rain data as a traffic risk guide driver route selection. Participant behaviour demonstrated the potential value of providing risk information in this way. Based on the results, we suggest that implementing voice alerts along with comparisons of risk and cost data represent the best approach. However, each function's effectiveness should be evaluated separately, and driving distraction should also be considered. In addition, there is a need for sociological research on traffic risks relating to how drivers think about the balance between risk and cost. Events that can tolerate high cost are important risk events. Further research will continue development and experiments aimed at improving the operation of this real-time system.

\section{References}

1. Kanae S, Oki T and Kashida A 2004 Changes in hourly heavy precipitation at Tokyo from 1890 to 1999 J. Meteorol. Soc. Japan 82 241-7

2. Japan Meteorological Agency 2019 Annual occurrence of rain at $50 \mathrm{~mm} / \mathrm{hour}$ or more (https://www.data.jma.go.jp/cpdinfo/extreme/extrem e p.html Date accessed: July 24, 2019)

3. Ministry of Land, Infrastructure, Transport and Tourism 201) White paper 2015 (http://www.mlit.go.jp/hakusyo/mlit/h27/hakusho/h 28/data/html/ns009040.html Date accessed: July 24, 2019)

4. Shankar V, Mannering F and Barfield W 1995 Effect of roadway geometrics and environmental factors on rural freeway accident frequencies Accid. Anal. Prev. 27 371-89 
5. Edwards J B 1999 The temporal distribution of road accidents in adverse weather Meteorol. Appl. 6 59-68

6. Jaroszweski D and McNamara T 2014 The influence of rainfall on road accidents in urban areas: A weather radar approach Travel Behav. Soc. 1 1521

7. Ivey D L, Lehtipuu E K and Button J W 1975 Rainfall and visibility: the view from behind the wheel J. Safety Res. 7 156-69

8. Hautière N, Dumont E, Brémond R and Ledoux V 2009 Review of the Mechanisms of Visibility Reduction by Rain and Wet Road

9. Horne W B and Dreher R C 1963 Phenomena of pneumatic tire hydroplaning (Washington, D.C.: National Aeronautics and Space Administration)

10. Uesugi $\mathrm{T}$ and Tanaka Y 2008 Occurrence structure of short-time heavy Rainfall in the center of Tokyo on 4 July 2000 Tenki 55 23-36 (in Japanese)

11. Takahashi N, Ushio T, Nakagawa K, Mizutani F, Iwanami K, Yamaji A, Kawagoe T, Osada M, Ohta T and Kawasaki M 2019 Development of multiparameter phased array weather radar (Mp-pawr) and early detection of torrential rainfall and tornado risk J. Disaster Res. 14 235-47
12. Zettsu K 2019 Integrated analysis platform for urban environment big data J. Environ. Conserv. Eng. 483 (in Japanese)

13. Kilpeläinen M and Summala H 2007 Effects of weather and weather forecasts on driver behaviour Transp. Res. Part F Traffic Psychol. Behav. 10288 99

14. Hofinger G, Zinke R and Künzer L 2014 Human factors in evacuation simulation, planning, and guidance Transp. Res. Proc. 2 603-11

15. Kato F, Monden H and Takase N 1992 An analysis of commuters' travel behaviors related to out-of-home, non-work activities under the constraints on a usable time J. Japan. Soc. Civil Eng. 449 97-106 (in Japanese)

16. Kahneman D 1973 Attention and Effort (Englewood Cliffs N.J.: Prentice-Hall)

17. Japan Meteorological Agency 2019 Class of rain and wind (https://www.jma.go.jp/jma/kishou/books/amekaze/ amekaze_index.html Date accessed: July 24, 2019)

18. Ito $\overline{\mathrm{S}}$ and Zettsu K 2019 Report on a hackathon for car navigation using traffic risk data Proc. 2019 3rd Int. Conf. Intell. Traff. Transport. (Amsterdam) 